\title{
Evaluating the Current Usage and Integration of ICTs in Education: A Review of Teachers' Usage and Barriers to Integration
}

\author{
Article by Caleb Moyo \\ Education, Texila American University, Zimbabwe \\ E-mail: cmoyo@texilaconnect.com
}

\begin{abstract}
This study examined current usage of information and communication technologies (ICTs) in a group of private secondary schools in Qatar and explored the barriers to effective integration of technology in Maths and Science lessons. The data was obtained from a total of 40 (18 female and 22 male) high school teachers. Results indicate that most teachers do not use ICTs as part of their pedagogical repertoire, instead, teachers reported using ICTs mostly for administrative work: - tracking attendance, preparing power point presentations, handouts and assessments. The article also reviews personal, institutional and technological factors that hinder teachers' use of computer technology in teaching and learning processes: - teacher-level, school-level and system-level. These barriers include lack of teacher ICT skills; lack of teacher confidence; lack of pedagogical professional development and a streamlined and effective school policy on ICT; lack of suitable and adequate educational software; limited access to ICT infrastructure and a restrictive curricula, amongst other factors. Teachers also made insightful suggestions on how to ameliorate the current situation. Implications of this study will help the group management and administration in planning, implementation and evaluation of effective integration of ICTs in teaching and learning within the group of schools, efficient use of limited technology infrastructure and resources, and improvement of access to learning for the students.
\end{abstract}

Keywords: ICT adoption; integration; barriers; teaching and learning.

\section{Introduction}

Information and communication technologies, (ICTs) are becoming increasingly important in our daily lives and in our educational systems. Therefore, there is a growing demand on educational institutions to use ICTs to teach the skills and knowledge students need for the $21^{\text {st }}$ century. ICTs are regarded as a factor in economic and social growth (World Bank, 2004). In many countries education has been selected by politicians as a means of bridging the gap between technology and society and for introducing new technology into society.

Realising the demands and effects of ICTs on the knowledge economy, educational institutions have attempted to restructure their educational curricula and facilities, in order to bridge the existing technology gap in the teaching and learning environments. The restructuring process requires effective adoption of technologies into existing ways of teaching and learning in order to provide learners with knowledge of specific subject areas, promote productive and meaningful learning and to enhance professional productivity (Tomei, 2005).

Research findings over the past 20 years provide some evidence supporting the positive effects of the use of ICTs on pupils' learning. In spite of such projects, the effects of numerous training programmes and investments by schools in ICT resources, there has been an agonisingly slow adoption and integration in schools (Cox et al, 1999; Passey \& Samways, 1997). Global investment in ICTs to improve teaching and learning in schools have been on the wish lists and initiated by many governments. For example in the United Kingdom, the government spending on educational ICT in 2008-09 in the UK was £2.5bn (NUT, 2010), in the United States, the expenditure on K-12 schools and higher education institutions was close to $\$ 6$ billion and $\$ 4.7$ billion respectively in 2009 (NUT, 2010) and in New Zealand, the government spends over \$ 410 million every year on schools ICT infrastructure (Johnson, Calvert \& Raggert 2009).

Despite all these investments on ICT infrastructure, equipment and professional development to improve education in many countries, Gulbahar (2007) claimed that huge educational investment have 
produced little evidence of ICT adoption and use in teaching and learning especially in countries like Turkey and those in the middle East. Evidence suggests that the education sector is investing heavily on ICT but ICT adoption in education sector has lagged behind the business sector (Leidner \& Jarvenpaa, 1995). Several surveys have been carried out to investigate the factors that are related to the use of computer technology in teaching and learning processes by teachers (Baek, Jung \& Kim, 2008; Norton, McRobbie, \& Cooper, 2000).

Many reasons for this lethargy have been reported, ranging from technical factors such as a lack of technology and software in schools and the limited expertise of teachers regarding ICT usage to other factors such as teachers' beliefs and knowledge about how to integrate ICT into teaching (Hsu \& Sharma, 2008; Jedeskog, 2005, Nivala, 2009; Pelgrum, 2001; Peralda \& Costa, 2007; Teo, Chai, Hung and Lee, 2008). Some writers have described these results in terms of waves where different technologies with intervals of three to four years have promised to deliver a revolution in teaching, learning and education but that, after a period of time, have sadly resulted in disappointment and little substantial educational change (Cuban, 1986, 2002; Gouseti, 2010; Rushby, 2005).

More so, it could be argued that the history of digital technologies in formal education has tended to promise a great deal but delivered far less. The gap between the optimistic talk surrounding ICT usage in education and the current level of ICT integration into educational settings has inspired researchers to focus on teachers and the difficulties they encounter integrating ICT tools into their classroom practices (Drent \& Melissen, 2008; Hsu et al., 2008; Pelgrum, 2001; Teknikdelegationen, 2010).

Identifying factors explaining ICT use is seen as a way of answering the question why some teachers embrace the use of technology with students in classrooms and others do not. These factors are often technology-related teacher characteristics where, for example, teachers' attitudes and self-efficacy are in focus (Herman, Tondeur, van Braak, and Valcke; 2008; Peralda et al., 2007; Teo et al., 2008).

Qatar has of late, been in the headlines for various reasons and has seen unparalled economic development at an astronomical pace which has also been accompanied by a proliferation of English medium schools within the education system. These schools may be individual and stand alone in terms of management hierarchy, or fall under a single governing body, i.e. a group of schools under the same name and more often than not, follow external curricula which compounds the problem of the use of English as a second language.

The more the number of campuses of the same governing body, the higher the need to streamline policies governing the choice and implementation of the curriculum, standardisation and uniformity of practice in all spheres. It is the focus of this study to examine the current status of ICTs in the different campuses under the same management structure: - Office of Standardisation, (OFSTAD), in as far as the adoption and integration is concerned in Maths and Science lessons.

The present study also tries to distance itself from viewing teachers as the main barriers in the implementation of ICTs in schools. The approach is multi-pronged as the factors needed to be categorised under different themes. Even if the rhetoric, deployment and use of ICT in educational settings remains challenging, there are teachers who do use ICT as a teaching and learning tool in their daily work with students in lessons, however this investigation was interested in identifying the particular factors affecting ICTs uptake and integration in the group of schools and proffer some solutions as suggested by teachers..

The analysis is based on the following research questions:

i. Which factors influence teachers' use of ICT in education?

ii. What is the current status of ICT usage in Maths and Science teaching and learning environments?

iii. What are the barriers to adoption and integration as perceived by the teachers?

\section{Research methodology}

In order to obtain a broader understanding of the nature and scope of teachers' use of ICT a survey study was undertaken. The main strength of survey research is the possibility to gather information from a larger sample of people, which is generally seen as a good method to employ if the aim of the study is also to acquire information about people's attitudes, beliefs and behaviour (Mitchell \& Jolley, 1996). The research instrument was a questionnaire that was distributed to selected high school teachers at the 
different campuses. The questionnaire was piloted to ascertain its construct validity and the necessary adjustments were made thereafter. This was followed by an observation checklist which corroborated the data from the questionnaire as well as a semi-structured interview to seek clarifications of some of the points raised in the questionnaires. These interviews were audio recorded and transcribed verbatim.

\section{Sampling method}

The target population in the present research were teachers in all the 10 secondary schools in Doha. In educational terms, Doha could be considered to be a cosmopolitan city, as there are many international schools within groups of schools which follow the National curriculum of England and Wales. The group of schools under study is one of the largest groups of schools in number and was chosen mainly for practical reasons, but also because the group contains demographic variations typical of the educational landscape as a whole in the country.

The selection of teachers was conducted using quota sampling. It is admissible that the main disadvantage of this type of sampling is that of the representativeness of the comparatively smaller sample. However the teachers needed to fulfil the requirements of being either Mathematics and/ or Science teachers. Generally speaking, it is hereby acknowledged that the larger the sample better, as this not only gives greater reliability also enables more sophisticated statistics, however a more rigorous statistical analysis was not a major thrust in the study. The results from the study may also not be generalizable to the greater population. Quota sampling emerges as an attractive choice when one is pressed for time, since primary data collection can be done in shorter time with this method compared to many alternatives. It can save costs and time.

Quota sampling is also independent of the presence of the sampling frames. Nonetheless, it is not possible to calculate the sampling error accurately and the projection of the research findings to the total population is risky. There is a great potential for researcher bias which was kept to a minimum.

\section{Methods}

The main data gathering methods were a survey questionnaire, semi structured interview schedule and a physical checklist to the respondents from the schools.

The questionnaire gathered demographic data, professional experience as well as that pertaining to ICT infrastructure as well as issues of adoption and integration. The questionnaire focused on teachers' perception of technology integration. It consisted of a number of subthemes that investigated teachers' perceptions of their technology competencies and usage, students' usage of technology, obstacles hindering technology integration, and the motives for teachers to integrate technology.

The questionnaire used a five-point Likert scale extending from 5 (very high or strongly agree) to 1 (very low or strongly disagree).

The semi structured interview collected detailed data on ICT competence, technology integration methods, problems hindering such integration, and incentives that increase integration in the classroom and also used to seek clarification on the issues raised in some responses from the questionnaire and the checklist was used to confirm the physical infrastructure in terms of hardware and software as well as the physical environments for the teaching and learning of Science and Maths. Simple descriptive statistics were used.

\section{Results}

Type and Extent of Teacher's Computer Use.

Table 1 presents the type and extent of computer use by teachers. The results indicated that teachers used computers often for preparing tests and lesson handouts for students $(\mathrm{n}=28,70 \%)$. The second highest computer use frequency was reported for homework assignments. Of the respondents $(n=35), 7$ teachers $(17,5 \%)$ indicated that they used computers for homework assignments to some extent. Another interesting point was that although the schools have purchased a number of instructional software packages installed on computers, more than half of the respondents $(56 \%)$ never used these software packages during teaching and learning. Only a very small number of teachers reported using instructional software regularly to enhance their classroom teaching (approximately 8\%). Finally, 
DOI: $10.21522 /$ TIJAR.2014.04.02.Art011

ISSN: $2520-3088$

teachers reported using computers less frequently for grading (5\%) and for administrative tasks $(45.6 \%)$.

Table 1. Type and extent of computer use by basic education school teachers

\begin{tabular}{|c|c|c|c|c|c|c|c|c|c|c|}
\hline $\begin{array}{l}\text { Frequency } \\
\text { Total never sometimes often dail }\end{array}$ & & & & & & & & & & \\
\hline USE TYPE & $\mathrm{N}$ & $\%$ & $\mathrm{~N}$ & $\%$ & $\mathrm{~N}$ & $\%$ & $\mathrm{~N}$ & $\%$ & $\mathbf{N}$ & $\%$ \\
\hline Creating Tests \& Handouts & & 100 & 5 & 14 & 22 & 55 & 8 & 20 & 5 & 12.5 \\
\hline Homework Assignments & 40 & 100 & 3 & 7.5 & 23 & 57.5 & 5 & 12.5 & 7 & 20 \\
\hline Administrative Tasks & 40 & 100 & 4 & 11 & 1 & 2.85 & 3 & 8 & 32 & 91 \\
\hline Testing \& Evaluation & 40 & 100 & 32 & 80 & 5 & 12.5 & 2 & 5 & 1 & 2.5 \\
\hline Grading & 40 & 100 & 28 & 70 & 7 & 17.5 & 5 & 122.52 & 0 & 0 \\
\hline Demonstration \& & 40 & 100 & 30 & 75 & 5 & 12.5 & 2 & 5 & 3 & 0.6 \\
\hline Drill \& Practice & 40 & 100 & 25 & 62.5 & 8 & 20 & 5 & 2.5 & 2 & 5 \\
\hline Tutorials & 40 & 100 & 33 & 82.5 & 5 & 12.5 & 2 & 5 & 0 & 0 \\
\hline $\begin{array}{l}\text { Telecommunications } \\
\text { (e-mail, web) }\end{array}$ & 40 & 100 & 0 & 0 & 2 & 5 & 4 & 10 & 34 & 85 \\
\hline
\end{tabular}

\section{Teacher's perceived computer competence}

Teachers were also asked to rate their perceived competence levels on common computer applications used in classroom situations. Means and standard deviations of teachers' self-perceived computer competence are shown in Table 2.

Table 2, shows that teachers rated themselves most competent on Word Processing ( $M=3.14$, SD $=0.86)$, whereas they rated lowest on instructional software use $(\mathrm{M}=1.86, \mathrm{SD}=1.04)$. Respectively, teachers felt themselves more competent on presentation software such as power point $(\mathrm{M}=2.70$, $\mathrm{SD}=1.02)$, spreadsheets $(\mathrm{M}=2.60, \mathrm{SD}=1.01)$, telecommunications $(\mathrm{M}=2.54, \mathrm{SD}=0.98)$, database $(\mathrm{M}=2.1$, $\mathrm{SD}=1.24)$, Web browsing $(\mathrm{M}=2.07, \mathrm{SD}=0.90)$ and desktop publishing $(\mathrm{M}=1.92, \mathrm{SD}=0.90)$. Teachers rated an average score $(\mathrm{M}=2.35, \mathrm{SD}=1.0)$ on the perceived computer competence scale.

Table 2. Teacher's perceived computer competency

Application Type N M SD

$\begin{array}{lclc}\text { Word processing } & 35 & 3.12 & 0.88 \\ \text { Database } & 35 & 2.1 & 1.24 \\ \text { Spreadsheet } & 35 & 2.59 & 1.01 \\ \text { Presentation Software } & 35 & 2.62 & 1.06 \\ \text { Web Browsing } & 373 & 352.07 & 0.90 \\ \text { Telecommunications } & 35 & 2.52 & 0.98 \\ \text { Educational Software } & 35 & 1.86 & 1.08 \\ \text { Desktop Publishing } & 35 & 1.92 & 0.92 \\ \text { OVERALL } & 2.35 & 1.0 & \end{array}$

\section{Follow-up interviews}

In order to identify the factors which contribute to teacher's ICT use in classrooms and to reveal their experiences with ICT and suggestions to overcome the obstacles that prevented them from effectively utilising ICT in classrooms, a questionnaire with 4 open-ended questions was distributed to the 40 teachers. Of the total respondents, $32(57.1 \%)$ agreed to give their perspectives on hindrances of ICT integration. The interviews were audio taped and transcribed for further analysis.

\section{Current conditions of ICT and classrooms in the schools}

The first question sought to indicate the current physical and technical conditions in the classrooms as well as teacher's current levels of access. Teachers' responses $(n=35)$ to this question indicated that the most significant impediment associated with access to ICT integration was the lack of adequate 
desktop or laptop stations. In most situations there was only one desk top for the use by the teacher and children had no hands-on experience as they had to contend with focusing on the whiteboard during teaching.

It was also indicated that a very small number of classrooms had access to interactive whiteboards (IWBs). Teachers reported that the average size of classes they taught ranged from 20 to 28 students which was considered to be ideal, but could not be supported by the current infrastructure.

From the responses it was evident that most teachers worked at schools with manageable class sizes, however some felt that there was no proper resource utilisation within the schools. For example, one teacher reported that "I have 30 learners in mv class and one computer in the room, I could book to use the IT room with my class, but the time table does not always allow and also it requires extra time which I do not usually have." Similarly, another teacher pointed out that "... 1 have to upload work on every computer before I take my class to the IT room and that takes too much time sometimes."

A number of teachers $(n=24)$ wrote that scheduling of IT rooms was another challenge since most schools did not have any concrete and acceptable systems of access and usage of ICTs within the school. It was left to the teacher to make an appointment with the teacher in the IT room. Teachers speculated on a wide range of causes for this challenge, varying from "lack of administrators' vision and knowledge on the use of ICTs in general and IT rooms in particular" to "lack of management's guidance and regulations on how IT rooms should be operated for access to all". The following statement from one teacher illustrates the extent of scheduling mix-up taking place in one school: " ... we don't have any schedules ... I cannot even take the learners there before making prior arrangements and sometimes there might even be a double booking."

Another important aspect is that of technical support services provided to teachers. There was a consensus among teachers $(n=37)$ that the quality of technical service was sometimes below expectations. Teachers indicated that either there wasn't any clear procedures of enlisting assistance of IT technicians or when they did know of the problem they normally took a long time to respond and that meant the teacher had to change lesson plans for a long period of time or abandon that approach. Another interesting comment written by one teacher was" ... why don't we leave management and maintenance of ICT rooms to students. Most are more knowledgeable than us. I am sure they would do a better job."

When asked about the Internet access, teachers reported that most schools had a dial-up connection that was relatively slow and could sometimes be off without much explanation from the technicians.

A number of teachers indicated that language is another barrier to ICT integration as another important obstacle to the use of Internet in schools $(n=20)$. Most useful sites for teachers on the Internet are predominantly in English, 'this limits the extent of usability to learners especially in the early grades in high school', and one respondent observed.

It is apparent from the responses provided for the first question that most teachers indicated on the rather poor technical service at their schools. Another issue raised by teachers was about the quality of Internet service in both It rooms and classrooms. They alluded to the slow connection to the Internet as a demotivating factor to students and sometimes contributed to poor behaviour and finally, teachers highlighted the need for the subscription to more interactive websites and computer assisted learning programmes to assist learners outside classes.

\section{Prevalence and quality of in-service ICT training and support}

The second question sought to delve into the prevalence and quality of organised ICT in-service programmes within the schools. Notably most respondents indicated that they did not have prior experience with ICTs in a pedagogical setting $(n=33)$, but had participated in in-service training programs in the past. These were said to have been too few and far in between. They reported having participated in at least one in-service training program or seminar on the use of ICT in teaching.

However, the teachers indicated a number of issues regarding the effectiveness of in-service training and why it did not address their immediate ICT skills needs. One of the issues reported by the teachers was that training programs were not tailored in accordance with their specific needs. There had been no prior needs analysis. The teachers expressed dismay at the fact that they taught different grades or subjects; and they attended the same once off professional development sessions irrespective of their 
individual needs. One teacher was even more emotional in her criticism "... I don't think ICT means the same thing to a Maths teacher than it does to a form tutor or a Physics teacher."

Teachers also extensively criticised the PD sessions as failing to provide hands-on activities and practice in reduced sessions $(n=34)$. Teachers reported that the PD sessions were also very short and $(\mathrm{n}=25)$ did not provide any opportunities for them to apply what they had learned. A number of teachers criticised the schools management for the haphazard manner in which these sessions were conducted, without a developmental approach which is cyclic and looks at skills development and generally, management's approach to the design and delivery of in-service training.

In summary, teachers' responses to the second question revealed that teachers did not think that the in-service training they received prepared them for teaching with technology. They thought that management should realign their adhoc approach to professional development and focus on fewer training objectives at a time, based on the actual needs of a teacher.

\section{Obstacles to the effective integration of JCT}

The third question delved into obstacles that hindered integration of ICT into their pedagogy. In their words, teachers indicated a variety of obstacles to the integration of ICT in the schools.

The most emergent obstacles reported by teachers are presented within the following categories:

\section{School curriculum}

More than half of the respondents $(n=26)$ expressed difficulty in finding time in which to fit ICT into their planning and teaching. Teachers felt that the curriculum is examinations based, it was therefore, primordial for them to cover the specifications for examinations whether internal or external. Hence they felt that ICTs use up a lot of preparation and teaching time. One teacher commented "I think the biggest obstacle ahead of ICT in the curriculum is that it has a lot of superfluous concepts and skills." Another teacher added "I know ICTs allow student engagement in more productive learning activities, but this is not examinable." The following statement from one teacher is quite interesting in terms of how management underestimate the value of ICTs in schools; " ... when the deputy head is here, s/he will be interested in the teacher's performance and on how much of the content has been covered in the class, and test scores of students, not the extent to which ICTs are used." From the teachers' responses it can be concluded that the examination system puts a lot of pressure on teachers to cover as much content as possible in a short space of time.

\section{Lack of Incentives}

In the current system, there is not much motivation for teachers to engage in innovative classroom practices since they are only paid for 40 hours per week, therefore, any extra load is considered as charity work. The time table is usually so congested that the only free time to attend any CPD would be during weekends, hence there is little motivation to put in that extra time and effort. Additionally students are not so keen to be in school for extra hours unless they are preparing for examinations. This issue was reported by a good number of teachers $(n=30)$.

\section{Lack of clear policy guidelines on ICT in the schools}

Teachers concurred in that schools had not yet provided clear policy guidelines on the usage of ICTs other than those governing their interaction with students and the wider community on social media. Some teachers even blamed their school administrators for lack of knowledge about the purpose ICTs in schools and for their lack of instructional leadership and technical pedagogical content knowledge.

\section{Lack of collaboration and collegiality among teachers}

Teachers indicated that they were not able to share best practice with other teachers' $(n=24)$. Some even reported that they were not aware of what other teachers teaching the same subject were doing in their schools since they were only given schemes of work which were not specific on ICT incorporation. A handful of teachers reported that such collaboration could contribute significantly to their ICT integration. 


\section{Dealing with the barriers, teacher suggestions}

As the last question in the follow up interview, the teachers were asked to give their perspectives on dealing with the hindrances to effective integration of technology in schools.

1. Timeous and tailored in-service training (in accordance with teacher's needs) should be provided at the local level $(\mathrm{n}=36)$ and if possible, even at subject level.

2. Timely and effective technical support should be provided for ICT rooms $(n=34)$.

3. The number of computers in classrooms should be increased to at least 20 per room or provision of a mobile laptop station could be done. $(n=38)$.

4. Effective incentive mechanisms should be available to motivate teachers towards the use of ICTs $(n=32)$ such as recognition and appropriate rewards.

5. School time-tabling should be such that it allows for the use of the ICT rooms for at least one double period a week $(n=37)$ per class or subject.

6. Every attempt to introduce ICTs in schools should be carried out with well-defined goals, policies and good praxis $(\mathrm{n}=37)$.

7. In-service training to all teachers, should be a matter of priority $(n=26)$.

8. Schools should procure ICTs according to their needs $(n=17)$ and purchase up-to-date software for teaching and learning.

9. Students could be encouraged to do their work on ICT applications at home and be rewarded for their work.

10. Schools could support teachers who engage in professional development programmes by financing their studies fully or in part.

\section{Discussion}

This study was conducted to examine the current utilization of ICTs in a group of schools of Qatar. Furthermore, this study attempted to reveal the barriers and obstacles that teachers believed prevented them from the effective integration of ICTs in classrooms. Finally, teachers' suggestions to overcome the obstacles were explored.

The findings of this study indicated that teachers largely used ICTs for creating handouts and tests, rather than using it to promote student's critical thinking skills and to foster their higher order cognitive abilities. Due to the lack of pedagogical technical support, teachers reported the lowest frequency for the use of instructional software. Additionally, teachers felt most competent on word processing whereas they felt least competent on the use of instructional software.

The follow-up interview revealed that in-service training was still a prevailing difficulty for many teachers to integrate technology in their classroom teaching. Some of the teachers belong to a different generation which did not have adequate training in the usage of ICTs in learning environments.

There is a large of body of research in the literature that supports the same position that teachers should could receive effective, timely and continuous training to promote technology in their teaching. (Wilson, Notar, \& Yunker, 2003; Yildirim, 2000; Yildirim \& Kiraz, 1999; Lemke, 1999; Northrup \& Little, 1997). There is a need to adequately plan for a developmental programme of ICT integration and related skills and knowledge.

Additionally, appropriate access to technology is another factor in the effective technology integration process (Norris et al, 2003). Teachers agreed that the use of ICT was only effective if every pupil in the class was assigned to authentic and meaningful instructional activities with sufficient number of computer workstations. Otherwise, computer lab sessions would only waste a teacher's and students instructional time; and further contribute to developing negative attitudes toward the use of ICTs among teachers.

It can also be deduced from the teachers' responses that the current curriculum could be arranged to incorporate the successful integration of ICTs. Teachers reported that they could have enough time or contextual support to seamlessly embed ICTs into the curriculum. This quarrel is also strengthened in the literature that curricula should be designed and mapped based on the principle that ICTs should be used by teachers and students as an inevitable tool to expressively explore and construct their own meanings among the concepts of various subjects (Vrasidas \& Mcisaac, 2001;Knapp \& Glenn, 1996; Ortega \& Ortega, 1995). 
Teachers expected strong educational leadership from the administrators and leaders for ICTs to cascade smoothly through the schools. Concurrently, in related literature, school principals and leaders are largely criticized for their reluctance to any kind of innovation penetrating into the system. Usually, their reluctance is attributed to their insufficient training and their tendency to preserve the status quo. Dawson and Rakes (2003) stressed that " ... without well trained, technology capable principles, the integration of technology into school curricula will remain incomplete." (p.46)

Finally, teachers underlined the paucity of incentives that they thought dampened their attempts to integrate the use of ICTs in their classrooms. Needless to say, recognition and promotion of those who could make productive use of technology in teaching will not only ensure the continuity of such practices, but also encourage others to invent their own practices of using technology.

Based on the findings from the present study, it is clear that the success of the group of schools' current endeavour to introduce ICTs largely depends on teacher's collaboration and their active involvement to the process. In order to ensure such collaboration and involvement, the governing body should develop and employ new policies to have teachers involved in the decision making and planning processes based on analysis of needs.

Unless the teachers are:

(1) Empowered through appropriate preservice and in-service training,

(2) Led by a powerful leadership,

(3) Provided with necessary incentives, and

(4) Continually provided with pedagogical technical content knowledge, the digital divide will be a perennial challenge in the group of schools.

\section{Conclusion}

There are, apparently various factors that influence and direct the process of adoption and integration of information and communication technologies in teaching and learning environments. These can be categorised into school factors, personal and external factors. It is concluded that teachers are willing to incorporate ICTs in their pedagogies, however there is need for clear guidelines in as far as ICT usage in the schools is concerned. Policy statements should not only be about communication with students and the community at large, but also refer to a workable systems that can be implemented and followed by all concerned so that ICTs can be accessible and used productively in teaching and learning. Instructional leadership must develop, implement and evaluate working ICT policies within the whole group of schools.

There is also a need for a developmental programme vis-a-viz continuing professional development within the schools. Teachers need to upgrade their skills in terms of the use of software for teaching purposes as well as the use of other computer related equipment such as interactive white boards. There is a strong consensus among teachers that the number of computer workstations in classrooms needs to be increased so as to be able to differentiate effectively during lessons. They also believe that behaviour could be controlled better with more computer workstations in classrooms.

Professional development needs to be looked at in a holistic manner including incentives and recognition for those teachers who make the extra effort to upgrade their skills.

The study recommends similar studies, however on a larger scale, so as to be able to ascertain the levels of adoption and integration of ICTs in teaching and learning environments in Maths' and Science. Professional development in terms of ICTs in learning would be more beneficial if planned through needs analyses so as to address the peculiar needs of the teachers. Further exploration is necessary to be able to come up with more useful CPD programmes within the group of schools. It could also be beneficial to explore the effect of language on the use of teaching and learning software programmes to students foreign to the English language. 


\section{References}

[1].Baum, J. A. C., \& Rowley, T. J. (Eds.). (2008). Advances in strategic management: Network strategy, vol. 25. Oxford: JAI/Elsevier

[2].Busch, T. (2011). Capabilities in, capabilities out: overcoming digital divides by promoting corporate citizenship and fair ICT. Ethics and Information Technology, 13(4), 339-353.MathSciNetCrossRefGoogle Scholar

[3].Castells, M. (2004). The network society: a cross-cultural perspective. Cheltenham: Edward Elgar Publishing.

[4].Chen, W., \& Wellman, B. (2004). The global digital divide - within and between countries. IT \& Society, $1(7), 39-45$.

[5].Cheney, K. E. (2007). Pillars of a Nation: child citizens and Ugandan development. Chicago: Chicago University Press.

[6].Corbin, J., \& Strauss, A. L. (2008). Basics of qualitative research: techniques and procedures for developing grounded theory (3rd ed.). Thousand Oaks: SAGE Publications.

[7].Creswell, J. W. (2009). Research design: qualitative, quantitative, and mixed methods approaches (3rd ed.). Thousand Oaks: SAGE Publications.

[8].Creswell, J. W. (2012). Qualitative inquiry and research design: choosing among five approaches (3rd ed.). Thousand Oaks: SAGE Publications.

[9].Evoh, C. J. (2007). Policy networks and the transformation of secondary education through ICTs in Africa: the prospects and challenges of the NEPAD e-schools initiative. International Journal of Education and Development Using ICT, 3(1), 64-84.

[10].Gholami, R., Higon, D. A., Hanafizadeh, P., \& Emrouznejad, A. (2010). Is ICT the key to development? Journal of Global Information Management, 18(1), 66-83.

[11].Hawkins, R. J. (2002). Ten lessons for ICT and education in the developing world. In G. Kirkman, P. Cornelius, J. Sachs, \& K. Schwab (Eds.), the global information technology report 2001-2002: readiness for the networked world (pp. 38-43). New York: Oxford University Press.

[12].Hite, J. M., Hite, S. J., Mugimu, C. B., \& Nsubuga, Y. (2010). Strategic "Co-opetition": Head teacher networking in Uganda's secondary schools. In A. J. Daly (Ed.), Social network theory and educational change (pp. 197-220). Cambridge: Harvard Education Press.

[13].James, J. (2001). Low-cost computing and related ways of overcoming the global digital divide. Journal of Information Science, 27, 385.

[14].James, J. (2011). Are changes in the digital divide consistent with global equality or inequality? The Information Society, 27(2), 121-128.

[15].Jhurree, V. (2005). Technology integration in education in developing countries: guidelines to policy makers. International Education Journal, 6(4), 467-483.

[16].Keniston, K. (2002). Grassroots ICT projects in India: some preliminary hypotheses. Information Technology in Developing Countries, 11(3), 60-64.

[17].Kozma, R., McGhee, R., Quellmalz, E., \& Zalles, D. (2004). Closing the digital divide: evaluation of the World Links program. International Journal of Educational Development, 24, 361-381.

[18].Marshall, C., \& Rossman, G. B. (2011). Designing qualitative research (5th ed.). Thousand Oaks: SAGE Publications.

[19].Richards, L. (2009). Handling qualitative data: a practical guide (2nd ed.). Thousand Oaks: SAGE Publications.

[20].UNESCO. (2010). EFA global monitoring report: reaching the marginalized. Paris: UNESCO.

[21].Uzunbolyu, H., \& Tuncay, N. (2010). Divergence of the digital world of teachers. Educational Technology \& Society, 13(1), 186-194. 